University of Warwick institutional repository: http://go.warwick.ac.uk/wrap This paper is made available online in accordance with publisher policies. Please scroll down to view the document itself. Please refer to the repository record for this item and our policy information available from the repository home page for further information.

To see the final version of this paper please visit the publisher's website. Access to the published version may require a subscription.

Author(s): Benjamin Smith, Claire Hill, Emma L. Godfrey, David Rand, Hugo van den Berg, Steven Thornton, Matthew Hodgkin, John Davey and Graham Ladds

Article Title: Dual positive and negative regulation of GPCR signaling by GTP hydrolysis

Year of publication: Forthcoming

Link to to published version:

Publisher statement: None 


\section{Dual positive and negative regulation of GPCR signaling by GTP hydrolysis}

Benjamin Smith $^{1 \dagger}$, Claire Hill ${ }^{2 \dagger}$, Emma L. Godfrey ${ }^{3 \dagger}$, David Rand ${ }^{4}$, Hugo van den Berg ${ }^{4}$, Steven Thornton $^{3}$, Matthew Hodgkin ${ }^{2}$, John Davey ${ }^{2}$ and Graham Ladds ${ }^{3 \pi}$

${ }^{1}$ Molecular Organization and Assembly of Cells Centre, ${ }^{2}$ Department of Biological Sciences, ${ }^{3}$ Division of Clinical Sciences Warwick Medical School and ${ }^{4}$ Systems Biology Centre University of Warwick Coventry CV4 7AL, UK

Running title: The dual role of GTP-hydrolysis in GPCR signaling

ฯ Corresponding author

Tel: $+44(0) 2476528361$

Fax: $+44(0) 2476523701$

Graham.Ladds@warwick.ac.uk

${ }^{\dagger}$ These authors contributed equally to this work.

Running title: The dual role of GTP-hydrolysis in GPCR signaling 


\begin{abstract}
G protein-coupled receptors (GPCRs) regulate a variety of intracellular pathways through their ability to promote the binding of GTP to heterotrimeric G proteins. Regulator of G protein signaling (RGS) proteins increase the intrinsic GTPase activity of G $\alpha$-subunits and are widely regarded as negative regulators of $\mathrm{G}$ protein signaling. Using yeast we demonstrate that GTP hydrolysis is not only required for desensitization, but is essential for achieving a high maximal (saturated level) response. Thus RGS-mediated GTP hydrolysis acts as both a negative (low stimulation) and positive (high stimulation) regulator of signaling. To account for this we generated a new kinetic model of the $G$ protein cycle where $G \alpha_{\text {GTP }}$ enters an inactive GTP-bound state following effector activation. Furthermore, in vivo and in silico experimentation demonstrates that maximum signaling output first increases and then decreases with RGS concentration. This unimodal, non-monotone dependence on RGS concentration is novel. Analysis of the kinetic model has revealed a dynamic network motif that shows precisely how inclusion of the inactive GTP-bound state for the G $\alpha$ produces this unimodal relationship.
\end{abstract}

Key words: GPCR; RGS; G protein; computational modeling; signaling 


\section{Introduction}

Vast numbers of cellular processes are regulated by the GTPase switch, including trans-plasma membrane signal transduction, control of cellular growth, vesicle and protein transport and cytoskeleton assembly. Increasing the number of GTP-bound G proteins enhances signaling, whereas increasing their intrinsic rate of GTP hydrolysis is believed to regulate the pathway negatively. Within signal transduction pathways, heterotrimeric G proteins (consisting of a nucleotide-binding $\mathrm{G} \alpha$-subunit plus $\mathrm{G} \beta \gamma$-subunits) couple cell surface-expressed receptors to intracellular effectors, in many different cell types. Active G protein-coupled receptors (GPCRs) promote nucleotide exchange on the $\mathrm{G} \alpha$-subunit, causing dissociation of the heterotrimer and subsequent effector activation [1,2]. Regulator of G protein signaling (RGS) proteins accelerate GTPase activity of the G $\alpha$-subunit (by acting as GTPase activating proteins; GAPs) thereby reducing production of second messengers from the effector $[3,4]$.

The pheromone-response pathway in yeast provides a model G protein-coupled signal transduction pathway that controls cell conjugation and division [5]. The binding of pheromones to receptors activates an effector system via the heterotrimeric $\mathrm{G}$ protein, to initiate intracellular changes that regulate the transcription of mating genes [6,7]. Yeast is therefore free from the complication of multiple receptors, effectors and other regulatory proteins [7]. RGS proteins were originally described in Saccharomyces cerevisiae as negative regulators of the pheromone-response pathway, where they minimize spontaneous cell activation and enable cells to recover from stimulation in the absence of conjugation [8]. In Sc. cerevisiae, G $\beta \gamma$-subunits stimulate effector activation, potentially making this pathway less affected by proteins that influence nucleotide hydrolysis on the Go-subunit [9]. In contrast the fission yeast Schizosaccharomyces pombe, utilized the $\mathrm{G} \alpha$-subunit of a classical heterotrimeric $\mathrm{G}$ protein, $\mathrm{Gpal}$, as its signal propagator of the pheromone-response pathway [10-12]. Briefly $S z$. pombe cells, during their mating cycle, grow up a pheromone gradient produced by a cell of the opposite mating type. The pheromones, (P-factor or 
M-factor) upon detection by mating type specific GPCRs, activates Gpal which propagates the

signal by promoting the activation of Ras1. This leads to stimulation of a mitogen-activated protein kinase (MAPK) cascade resulting in the activation of the transcription factor Ste1 1 [6,9]. In addition to the transcription of pheromone-dependent genes, Sz. pombe also undergoes a morphological change in response to pheromone. Responding cells continue to grow from the tip of the cell and elongate towards the source of the pheromone forming a shmoo [13]. It currently remains unknown how Gpa1 activates both pathways.

Deletion of $r g s 1$ in $S z$. pombe increases ligand-independent signaling and reduces mating efficiency [14-16], which suggests that Rgs1 acts as a negative regulator of the pheromone-response as reported in Sc. cerevisiae [7]. Here we demonstrate that at high ligand concentrations, Rgs1 also plays a positive role in regulating the pheromone-response. Through targeted mutational analysis, we alter the GTPase activity on Gpa1 to demonstrate that GTP-hydrolysis is absolutely required to achieve maximum signaling.

A mathematical model has been developed that reproduces in vivo data, and provides a novel mechanistic description of the $G$ protein signaling pathway. Crucial to the faithful reproduction of the observed phenomena is the assumption that one $G \alpha_{G T P}$ activates only one effector molecule per round of guanosine nucleotide exchange and hydrolysis. Entry into an inactive but GTP-bound state following the activation of an effector removes the $\mathrm{G} \alpha_{\mathrm{GTP}}$ from the pool of molecules available for signaling, rather than allowing further effector activation by the same molecule. GTP hydrolysis, accelerated by an RGS protein, releases the $\mathrm{G} \alpha$ from this inactive GTP-bound state and allows subsequent reactivation by ligand-bound receptors and then activation of another effector molecule. Parallel in vivo and in silico experiments reveal a non-monotone relationship with a single maximum (i.e. unimodal) between pathway output and quantity of RGS protein. This non-monotone relationship reflects the dual positive/negative character of RGS regulation. An abstract dynamic network motif that captures the underlying structure of the more complex mathematical model is used to derive the non-monotone relationship explicitly. Finally, 
comparison of this motif with an alternative motif, whose structure underlies many current models

1

2

3

4

5

6

7

8

9

10

11

12

13

14

15

16

17

18

19

20

21

22

23

24

25

26

27

28

29

30

31

32

33

34

35

36

37

38

39

40

41

42

43

44

45

46

47

48

49

50

51

52

53

54

55

56

57

58

59

60

61

62

63

64

65 of $\mathrm{G}$ protein signaling, shows why these current models are unable to account for non-monotone regulation by the RGS. 


\section{Materials and methods}

\section{$2.1 \quad$ Strains, reagents and general methods}

The effector output from the pheromone-response pathway in $S z$. pombe can be quantified using pheromone-dependent transcription of $\beta$-galactosidase expressed from the $\operatorname{sxa} 2>\operatorname{lac} Z$ reporter construct as described previously [16,17]. All yeast strains (Supplementary table S9) have been described previously $[12,16]$ with the exception of JY1340 which was derived from JY546 but had gpal replaced with $g p a 1^{G 223 S}$. Gene replacements were confirmed by polymerase chain reaction (PCR) and Southern blot analysis. General yeast procedures were performed as described [18,19]. Oligonucleotides were synthesized by Invitrogen Ltd. (Paisley, Scotland, UK). Amplification by PCR used Pwo DNA polymerase (Boehringer Mannheim Biochemicals, Lewes, UK) or KOD HiFi DNA polymerase (Merck Chemicals Ltd., Nottingham, UK). All constructs generated by PCR were sequenced.

\subsection{Assay of $\beta$-galactosidase activity}

$\beta$-galactosidase assays in $S z$. pombe cells were performed as described previously [16,20]. Sz. pombe cells were cultured to a density of $\sim 5 \times 10^{5}$ cells $\mathrm{ml}^{-1}$ in DMM and $500 \mu$ laliquots transferred to 2-ml Safe-Lock tubes (Eppendorf, Hamburg, Germany) containing $5 \mu 1$ of P-factor (in HPLC-grade methanol). Tubes were incubated at $29^{\circ} \mathrm{C}$ for $16 \mathrm{~h}$ on a rotating wheel, and $50 \mu \mathrm{l}$ transferred to $750 \mu \mathrm{l}$ Z-buffer containing $2.25 \mathrm{mM} o$-nitrophenyl- $\beta$-D-galactopyranoside (ONPG). Reactions were stopped after $90 \mathrm{~min}$ by adding $200 \mu \mathrm{l}$ of $2 \mathrm{M} \mathrm{Na}_{2} \mathrm{CO}_{3}$ and $\beta$-galactosidase activity calculated as optical density at $420 \mathrm{~nm}\left(\mathrm{OD}_{420}\right)$ per $10^{6}$ cells (determined using the $\mathrm{Z} 2$ Coulter Channelyzer) (Beckman Coulter, Luton, UK).

\subsection{Plasmids}


pREP3x contains the LEU2 gene and pREP4x contains the ura4 gene, both of which were

controlled by thiamine-repressible $n m t 1$ promoter [21]. The production of all Gpal constructs with the exception of Gpa1 ${ }^{\mathrm{Q} 24 \mathrm{~L}}$, have been described [12]. Gpa1 ${ }^{\mathrm{Q} 244 \mathrm{~L}}$ was generated by bipartite PCR [22] on the wild type constructs. Generation of pREP3x-Rgs1 and pREP4x-Rgs1 was described previously [12]. Mutant Rgs1 constructs were generated by inverse PCR on wild type rgs 1. GFP constructs were made using a two-step cloning technique described previously [17].

\subsection{Model simulations}

A chemical kinetic model, based upon the reaction scheme shown in Fig. 3, using a system of ODE was solved using the xCellerator (California Institute of Technology, Pasadena, CA) add-on package for Mathematica v5.0 (Wolfram Research Inc, Champaign, IL). Experimental strains were simulated by altering the relevant reaction rate constants and initial conditions (Supplemental Table S3). Data were analyzed using linear and non-linear regression as appropriate using GraphPad Prism v4.03 (GraphPad Software Inc, San Diego, CA). 


\section{Results}

\subsection{GTP hydrolysis is essential for maximal signaling in a GPCR-stimulated pathway}

Previous studies have indicated that Rgs1 is essential for mating in Sz. pombe [14-16]. Utilizing modified yeast strains where the pheromone-inducible gene sxa2 has been replaced with bacterial $L a c Z$ gene [16] we demonstrate that unstimulated cells, deleted for $r g s 1$ ( $\Delta$ Rgs1 in Fig. 1A), display a 4-fold increase in signaling compared to cells expressing Rgs1 (Fig. 1A) (deletion of rgs 1 does not affect receptor or $\mathrm{G}$ protein expression; data not shown). Further, rgs 1 deletion also increases yeast's sensitivity to pheromone stimulation $\left(\mathrm{pEC}_{50} ; \operatorname{Rgs} 1=6.8 \pm 0.05, \Delta \operatorname{Rgs} 1=8.3 \pm 0.1\right)$. These results are consistent with the notion that RGS proteins act as negative regulators of signaling. However, when stimulated with pheromone concentrations $\geq 1 \mu \mathrm{M}, \Delta r g s 1$ cells show a $\sim 2$-fold increase above ligand-independent levels, compared to a $\sim 15$-fold increase for cells expressing wild type Rgs1. The absolute level of signaling at saturating pheromone concentrations is therefore much higher in cells containing Rgs1 than those lacking it. This suggests that the effects of Rgs1 on the G protein-coupled pheromone-response pathway vary with ligand concentration. In the absence of pheromone, or at low pheromone concentrations, Rgs1 suppresses Gpal signaling. However, at higher ligand concentrations, the presence of Rgs1 facilitates increased effector output and therefore potentiates signaling through the pathway. To date, RGS proteins are most often reported as negative regulators of signaling $[3,4]$. Thus the observation presented here that RGS proteins increase the maximal capacity of a pathway, represents a novel role for these proteins.

The interaction of RGS proteins with a G $\alpha$-subunit can be blocked by mutating a conserved glycine to serine [23], which in Gpal corresponds to glycine 223 [12]. We directly replaced the wild type chromosomal copy of Gpa1 with Gpa1 ${ }^{\mathrm{G} 223 \mathrm{~S}}$. Cells expressing Gpa ${ }^{\mathrm{G} 223 \mathrm{~S}}$ exhibit a phenotype almost identical to a $\Delta r g s 1$ strain containing wild type Gpal (Fig. 1A). Expression of the $\mathrm{Gpa}^{\mathrm{G} 223 \mathrm{~S}}$ from a plasmid resulted in an attenuated pheromone-response similar to that observed when expressed chromosomally (Fig. 1B). By comparison, expression of Gpal from a plasmid in 
strains where the chromosomal copy of gpal had been deleted resulted in normal pheromone

sensitivity and responsiveness (compare Fig. 1B with Fig. 1A).

The GTPase activity of the $\mathrm{G} \alpha$-subunit of heterotrimeric $\mathrm{G}$ proteins can be manipulated by mutating critical residues in the switch region II $[24,25]$. Versions of Gpa1 were expressed from plasmids (which give equivalent expression levels to chromosomally integrated versions [12]) in strains where the chromosomal copy of gpal had been deleted (Fig. 1B), with and without deletion of chromosomal rgs1 (Fig. 1C). Mutation of glutamine 244 (to leucine) generated a GTPase deficient Gpa1 $[8,10,23]$. This mutation displayed constitutive activity, increased pheromone sensitivity $\left(\mathrm{pEC}_{50}\right.$; pGpa1 $\left.=6.775 \pm 0.046, \mathrm{pGpa}^{\mathrm{Q} 244 \mathrm{~L}}=7.209 \pm 0.3\right)$ and a level of maximal signaling approximately half that of wild type levels. Deletion of chromosomal rgs 1 reduced signaling in strains expressing plasmid-borne wild type Gpal but had no additional effect on the GTPase deficient mutant (Fig. 1C). Therefore the GTPase activity of Gpal is essential for cells to achieve maximal pheromone-induced signal transduction.

In strains where rgsl had been deleted, over-expression of Gpa1 increased both ligandindependent and maximal signaling (at pheromone concentration $\geq 1 \mu \mathrm{M}$; Fig. 1D) and increased ligand sensitivity. Expression of an additional copy of Gpal also increased maximal signaling in the presence of Rgs1. Taken together these data demonstrate that the decrease in maximal signaling observed in the absence of Rgs1 is due to a reduction in the effective concentration of $\mathrm{G} \alpha$-subunits available for GPCR activation. Thus, we suggest that maximal effector activation requires Rgs1catalyzed increases in GTP hydrolysis by the G $\alpha$-subunit.

\subsection{Deletion of Rgs1 reduces the duration of the response}

A reduction in the cells ability to hydrolyze GTP upon Gpal results in an attenuated maximal pheromone induced signaling response while previous observations have indicated that $S z$. pombe strains deleted for Rgs1 display a reduced mating efficiency [14,15]. We hypothesized that the attenuation of maximal signaling, coupled to reduced mating efficiency might result from a loss of 
the cells ability to temporally detect changes in the pheromone gradient. Thus, cells containing or

lacking Rgs1 were compared of their time- and dose-dependent signaling characteristics over a $16 \mathrm{~h}$ time-frame [16]. For cells expressing Rgs1, $\beta$-galactosidase was detectable at times consistent with sxa2 expression (observed after $4 \mathrm{~h}$ ) reaching a plateau after $10 \mathrm{~h} \mathrm{[16].} \mathrm{This} \mathrm{was} \mathrm{in} \mathrm{contrast} \mathrm{to} \mathrm{the}$ profiles observed for cells deleted for Rgs1 which displayed increased ligand-independent signaling (Fig. 2) and appeared to achieve their maximal level of signaling after 4-6 h post simulation (Fig. 2C). In addition, similar observations were achieved for strains expressing Gpa ${ }^{\mathrm{G} 223 \mathrm{~S}}$ and Gpa $1^{\mathrm{Q} 244 \mathrm{~L}}$ (data not shown). These results suggest that the deletion of Rgs1 reduces maximal signaling by attenuating the duration of the response and is consistent with the notion that there is a reduction in the effective concentration of active $\mathrm{G} \alpha$ subunits. We suggest, based upon the data shown in Figures

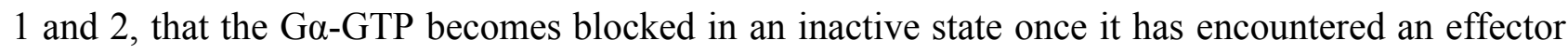
molecule.

\subsection{Modeling of the GTPase cycle}

The observation that RGS activity has a positive effect on GPCR signaling contradicts the consensus that these proteins function as negative regulators [3,4]. Therefore the existing reaction schemes describing receptor-stimulated GTPase cycles, including those generated in yeast, could not be used to simulate our observations (see [26-32] and Supplementary text. We therefore formulated a new mechanistic hypothesis for the GTPase cycle that allows RGS proteins to act as both negative and positive regulators of effector output. This is presented as a reaction scheme in the Supplementary table S1) and shown schematically in Fig. 3. The reaction scheme is based upon the currently identified components within $S z$. pombe that regulate the $\mathrm{G} \alpha$-mediated pheromone response.

We suggest that at low concentrations of ligand-bound receptor (LR), when only small amounts of $G \alpha_{G T P}$ are generated, the RGS protein increases the rate of GTP hydrolysis, significantly limits effector activation (parameter $\mathrm{k}_{7}$ in Fig. 3) which is acting as a negative 
regulator of signaling. Consequently, removing the RGS protein allows more Ga $\alpha_{\text {GTP }}$ to encounter

and activate effectors (parameter $\mathrm{k}_{10}$ ). At high ligand concentrations, a much larger proportion of the total pool of $G \alpha_{G D P}$ is converted to $G \alpha_{G T P}$ by the stimulated receptor, overwhelming the negative regulatory role of the RGS proteins which enables the effector system to become activated despite the presence of the RGS. Up to this point the mechanism is in broad agreement with published schemes [26-32]. Achieving the positive effect of RGS activity necessitated the inclusion of a second term for a GTP-bound $\mathrm{G} \alpha$-subunit ( $\left.\hat{\mathrm{G}} \alpha_{\mathrm{GTP}}\right)$ specifically generated following an encounter with an effector; this constitutes a "post-signaling" state for the G protein. We suggest that $\hat{\mathrm{G}} \alpha_{\mathrm{GTP}}$ takes no further part in signaling until it has hydrolyzed its GTP in a reaction that can be accelerated by the RGS protein. At high levels of ligand stimulation, when the rate of guaninenucleotide exchange has become greater than the rate of pre-signaling hydrolysis, signal amplification is, in effect, subject to a positive feedback loop. This arises because both presignaling $\mathrm{G} \alpha_{\mathrm{GTP}}$ and post-signaling $\mathrm{G} \alpha_{\mathrm{GTP}}$ compete for the RGS. Consequently, the amount of free $\mathrm{G} \alpha_{\mathrm{GTP}}$ is increased because the negative role (pre-signaling hydrolysis) is reduced and the positive role (turnover of post signaling $\hat{\mathrm{G}} \alpha_{\mathrm{GTP}}$ ) is accelerated.

\subsection{Using mathematical modeling to characterize the novel GTPase cycle}

Mathematical and computational modeling has a long history in the GPCR field and offers a powerful tool for testing alternative hypothesis relating to the GTPase cycle. Such models can be used to understand conflicting hypotheses, run virtual experiments and offer new explanations for observed phenomena [33]. We therefore performed in silico simulations based upon a system of ordinary differential equations (ODEs) that describe the reaction scheme presented in Fig. 3 (see Supplementary text, tables, figures and equations). The pathway was modeled empirically and tested to determine its ability to provide sufficient regulatory flexibility to reproduce the in vivo data. Due to incomplete quantitative data for all rate constants and species concentrations, strong qualitative agreement between simulations and in vivo data was desired. Parameter values were 
hand-tuned to fit with in vivo experimental data. The cellular concentration for the GPCR - Mam2

has been determined to be $205 \mathrm{nM}$ [17]. Although the precise Gpal concentration remains to be determined in Sz. pombe, as in many other published models [26-32], we have used a ratio of 1:1 for GPCR concentration to G $\alpha$ concentration. Our concentration of the RGS species was estimated to be 4-fold lower than the Gpa1/Mam2 concentration $(60 \mathrm{nM})$ and is in agreement with that observed for other RGS proteins [27,30,32,34]. All reactions were assumed to occur with net forward direction using mass action kinetics similar to several models of $\mathrm{G}$ protein mediated signaling pathways $[27,28,32]$. To enable simplicity of or modeling, we have included more detail about the G protein activation/deactivation cycle than the downstream MAP kinase cascade. Our choice of parameters is based upon the response kinetics that we observed in the time course assay shown in Fig. 2. Our in vivo response is measured by detecting the accumulation of $\beta$-galactosidase. We simulated this by determining the integral of the number of active effector molecules ( $\mathrm{G} \alpha_{\mathrm{GTP}} \mathrm{Effector}$ ) after applying a cascade of linear relaxation elements (Supplemental text). A detailed parameter sensitivity analysis will be published elsewhere.

While our model may not contain all possible reactions as such could be described as rather 'simple', it was able to reproduce the observed biological responses for both the time- and dosedependent effects of an agonist on an effector system in the presence or absences of RGS activity (compare Fig. 4 to Fig. 2; a comparison of $\mathrm{pEC}_{50}$ values is shown in the Supplementary table S8). We simulated the effect of altering G protein activity and concentration in the model in the presence and absence of a functional RGS activity. An RGS-insensitive version of the G protein, equivalent to mutating glycine 223 in Gpa1, was generated within the model by preventing the association of RGS with the G protein both before and after effector interaction (parameters $\mathrm{k}_{7}$ and $\mathrm{k}_{12}$ reduced to zero). Output from the model containing an RGS-insensitive G protein behaved the same as when RGS was deleted from the model, thus reproducing the in vivo data (compare Fig. 5A to Fig. 1A). Both in the presence or absence of an RGS, parameters controlling GTPase activity were set to zero (parameters $\mathrm{k}_{8}, \mathrm{k}_{9}, \mathrm{k}_{13}$ and $\mathrm{k}_{14}$ ), generating the equivalent of a GTPase deficient $\mathrm{G}$ protein. Here too, 
output from the model accurately reproduced the effect of in vivo mutation of glutamine 244 to

leucine (compare Fig. 5B and 5C with Fig. 1B and 1C). To simulate over-expression of Gpa1, the concentration of G $\alpha$ was doubled within the model in the presence and absence of RGS activity. Again the model was able to accurately reproduce our in vivo data (compare Fig. 5D with Fig. 1D). The model qualitatively simulates the effects of altering $\mathrm{G}$ protein activity and availability within the pathway, as well as predicting the dual roles of RGS activity in regulating GPCR signal transduction.

In some GPCR signaling systems, for example the pheromone-response pathway in Sc. cerevisiae, the $\mathrm{G} \beta \gamma$, rather than the G $\alpha_{\mathrm{GTP}}$, propagates downstream signaling [7]. We investigated whether our modified computational model was able to simulated G $\beta \gamma$-mediated pathways. Conversion of the signal propagator from $G \alpha_{\mathrm{GTP}}$ to $\mathrm{G} \beta \gamma$, in the presence of RGS activity, preserved the shape of the ligand-response profile whilst total effector output increased 6-fold (compare Fig. 5A with Fig. 5E). Removal of RGS activity resulted in increases in ligand-independent signaling, ligand-dependent responsiveness $\left(\mathrm{pEC}_{50} ; \mathrm{RGS}=7.3 \pm 0.023, \Delta \mathrm{RGS}=6.6 \pm 0.021\right)$ and maximal effector output (Fig. 5E). Within this modified model, setting the parameters controlling GTPase activity to zero (mimicking a GTPase deficient Ga subunit) generated an effector output profile almost identical to that obtained when RGS activity was removed (Fig. 5E). So in systems of this kind, RGS proteins appear only able to negatively regulate signaling.

\subsection{Maximal effector output requires $R G S$-dependent recycling of $G \alpha_{G T P}$}

In a system with $G \alpha_{\mathrm{GTP}}$ as a signal propagator the amount of intracellular $\mathrm{G} \alpha_{\mathrm{GTP}}$ produced is clearly critical to controlling output. Since RGS proteins accelerate hydrolysis and hence regulate the amount of free $G \alpha_{\mathrm{GTP}}$ available, the system should be profoundly sensitive to their concentration. Simulating a doubling $(120 \mathrm{nM})$ or trebling $(180 \mathrm{nM})$ of RGS concentration within the model (Fig. $6 \mathrm{~A})$, reduced the sensitivity of the system to ligand such that the predicted $\mathrm{EC}_{50}$ value for ligandstimulated effector activation was reduced by 4 -fold and 8 -fold respectively. This effect of 
increased RGS concentration on sensitivity to ligand stimulation is consistent with the widely

accepted role of RGS proteins as negative regulators of signaling. On the other hand, the novel positive role played by RGS proteins within the signaling pathway is further evident from the 1.5fold increase in maximal effector output when the RGS concentration is doubled from $60 \mathrm{nM}$ to 120 $\mathrm{nM}$. The model predicts that with further increase in RGS concentration, to $180 \mathrm{nM}$, maximal effector output is reduced to half that occurring at $60 \mathrm{nM}$, putting it at a level similar to that produced when the RGS is removed. Thus, for obtaining high maximum output, an RGS concentration of $120 \mathrm{nM}$ is optimal according to the model simulations.

To test the predictions of doubling the RGS concentration in yeast, the endogenous Rgs1 concentration expressed from the chromosomal copy of the gene was increased by introduction of a plasmid-borne copy of the gene. To increase the Rgs1 concentration further an additional plasmid was used to express a third copy of the gene so trebling the RGS concentration. Expression of Rgs 1green fluorescent protein (GFP) from one or two different plasmids together with chromosomal expression demonstrated that fluorescence increased linearly with increased protein expression (data not shown). Chromosomal and plasmid derived copies of Rgs1 exhibited equivalent effects upon pheromone signaling (see Supplemental Fig. S4). The results in Fig. 6B show that an increase in Rgs1 concentration, generated by the addition of a plasmid expressing Rgs1, in the yeast increased maximum effector output (1.6-fold) and reduced sensitivity in response to pheromone $\left(\mathrm{pEC}_{50} ; 1 \times \operatorname{Rgs} 1=6.88 \pm 0.05,2 \mathrm{xRgs} 1=6.08 \pm 0.05\right)$, in agreement with predictions from the computational model. Importantly, increasing the Rgs1 intracellular concentration by approximately 3-times reduced pheromone sensitivity by 10 -fold when compared to $1 \times \operatorname{Rgs} 1\left(\mathrm{pEC}_{50} ; 3 \mathrm{xRgs} 1=\right.$ $5.85 \pm 0.1)$ and, as predicted by the model, also attenuated maximal effector output. These data demonstrate that the dual role for Rgs1 within the signal transduction pathway is concentrationdependent.

The data in Fig. 6A and 6B suggest a non-monotone relationship between the signaling output and the RGS concentration. To investigate this relationship in more detail, a simulation of 
signaling output against RGS concentration between $0 \mathrm{nM}$ and $200 \mathrm{nM}$ was plotted for a number of

ligand concentrations (Fig. 6C). In the absence of stimulation or at low levels of ligand (1-10 nM), modest increases in RGS concentration (0-30 nM) rapidly abolishes effector output. However, at higher concentrations of ligand $(>100 \mathrm{nM})$, increased RGS concentration acted positively to enhance signaling until a maximum was reached where the negative inhibitory effects again predominated. Similar analysis of the in vivo data (Fig. 6D), shows agreement with the in silico predictions Fig. 6C. It is interesting to note when RGS concentration reaches $180 \mathrm{nM}$ (3-times endogenous levels) the negative role of the RGS activity dominates at all ligand concentrations. We suggest that the transition between the positive and negative roles of RGS activity within the GPCR pathway appears to be dependent on both the concentration of RGS and the concentration of $G \alpha_{G T P}$ generated by ligand-bound-receptors.

\subsection{A dynamic network motif}

To determine precisely how complex signaling networks function, it is often useful to identify the simplest network structure or motif [35]. Such motifs allow us to explicitly determine the system's dependence on the parameters and the effects of perturbations on its output. Furthermore, analysis of the structure of different models facilitates comparison between competing hypotheses.

A network motif was identified (Fig. 7A) that captures the underlying structure of the more complex model of the G protein GTPase cycle presented in this paper. The network has both a presignaling state $\left(\mathrm{X}^{[1]}\right.$, analogous to $\left.\mathrm{G} \alpha_{\mathrm{GTP}}\right)$ and a post-signaling state $\left(\mathrm{X}^{[2]}\right.$, analogous to $\left.\hat{\mathrm{G}} \alpha_{\mathrm{GTP}}\right)$ for the signaling molecule $(\mathrm{X})$ both of which can be bound by the regulatory molecule ( $\mathrm{R}$, analogous to the RGS protein). Subsequent to formation of the complexes $\mathrm{R}^{[1]}$ and $\mathrm{R}^{[2]}$, the signaling molecule is converted back to its basal state $\left(\mathrm{X}^{\circ}\right)$ and free regulatory molecule $\left(\mathrm{R}^{\circ}\right)$ is released. Fig. 7B demonstrates that this motif produces the non-monotone relationship, as found experimentally, between maximum steady state output flux and quantity of regulatory molecule at maximum stimulation. By contrast, a network motif (Fig. 7C) that possesses no post-signaling state, abstracted 
from existing models [26-32], produces a relationship between maximum steady state output flux

that is a monotone decreasing function of the amount of regulatory molecule (Fig. 7D). Thus, a network motif lacking a post-signaling state is unable to account for the non-monotone behavior shown in Fig. 6.

The explicit relationships produced through the mathematical analysis (detailed in the Supplementary text) of the network motifs are largely insensitive to parameter values (rate constants must only be real and positive). Thus we confirm, in a parameter-independent way, that it is the addition of a post-signaling state that also may be bound by the regulatory molecule, which endows the system with the observed dynamical properties. 


\section{Discussion}

\subsection{GTP hydrolysis is essential for maximal signaling in Sz. pombe}

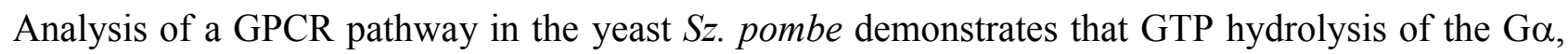
rather than retention of a GTP-bound state, is essential for maximal response to pheromone. Thus $\mathrm{G} \alpha_{\mathrm{GTP}}$ cannot continually activate effectors and we suggest that one $\mathrm{G} \alpha$ activates one effector per GTP hydrolysis event. Consequently RGS proteins (that act as GAPs for $\mathrm{G}_{\mathrm{GTP}}$ ) can act as positive regulators of signaling by accelerating conversion of $G \alpha_{\mathrm{GTP}}$ to $G \alpha_{\mathrm{GDP}}$ and returning the inactive $\mathrm{G} \alpha$-subunits to ligand-occupied receptors, enabling their reactivation. Our conclusions are derived from three key observations. First, at high levels of stimulation, the GTPase-enhancing activity of Rgs1 was required to maximize effector output (Fig. 1A, Fig. 2 and Fig. 6D). Secondly, the use of a GTPase-deficient mutant of Gpa1 (Gpa $\left.{ }^{\mathrm{Q} 244 \mathrm{~L}}\right)$ demonstrated that GTP hydrolysis is essential for maximal signaling (Fig. 1B and 1C). Thirdly, increasing the intracellular Gpal concentration increased effector output in the presence or absence of Rgs1 (Fig. 1D). From this we infer that removal of the RGS protein reduces effector output by decreasing the supply of $\mathrm{G \alpha}_{\mathrm{GDP}}$ available to be re-activated by ligand-occupied GPCRs. Since in the absence of RGS activity, the intrinsic rate of GTP hydrolysis by $G \alpha$-subunits is slow, we propose that $\mathrm{G} \alpha$-subunits attain a post-signaling GTP-bound conformation following their encounter with an effector (which we denote $\hat{\mathrm{G}} \alpha_{\mathrm{GTP}}$ ). Only by the hydrolysis of the bound nucleotide, in a reaction that is significantly enhanced by an RGS protein, can $\hat{\mathrm{G}} \alpha_{\mathrm{GTP}}$ be returned to the pool of $\mathrm{G} \alpha$ subunits available for subsequent receptor activation. A reaction scheme revised to incorporate this new hypothesis (Fig. 3) encompasses a second GTP-bound state for Ga, from which GTP hydrolysis is the only possible exit. Model simulations were in broad agreement with experimental data, whereas other models tested (based on [26-32], as well as several of our own competing hypotheses; see Supplementary text) failed to adequately describe the same data. The agreement between model and experiment strongly suggests that an RGS protein can both positively and negatively regulate $\mathrm{G}$ protein signaling and achieves this through its GTPase-accelerating activity. 
Further evidence for the existence of post-GTP hydrolysis conformational states capable of regulating effectors, has been provided by the use of $\mathrm{G} \alpha$-subunit mutants which trapped intermediates within the $\mathrm{G}$ protein cycle [36]. The possibility that $\mathrm{G}$ proteins can enter alternative GTP-bound states has been further raised by the existence of a tetra-co-coordinated transition state $\left(\mathrm{G}_{\mathrm{GTP}}^{\ddagger}\right)$ in the hydrolytic mechanism (reviewed [3]). This intermediate may be mimicked experimentally through the use of $\mathrm{AlF}_{4}^{-}$binding to $\mathrm{G}_{\mathrm{GDP}}$ [36] although it remains to be determined if $\hat{\mathrm{G}} \alpha_{\mathrm{GTP}}$ resembles $\mathrm{G \alpha}_{\mathrm{GTP}}^{\ddagger}$ or $\mathrm{G}_{\mathrm{GDP}^{*}} \mathrm{AlF}_{4}^{-}$. It is of paramount importance that we now biochemically prove the existence of our $\hat{G} \alpha_{\mathrm{GTP}}$ both in vivo and in vitro. Finally, our suggestion that one G $\alpha$ activates one effector per GTP hydrolysis event has been proposed for the activation of phospholipase $\mathrm{C} \beta$ (PLC) by mammalian $\mathrm{G \alpha}_{\mathrm{q}}$. In addition to its role as an effector, PLC functions as a GAP for $\mathrm{G \alpha}_{\mathrm{q}-\mathrm{GTP}}$ promoting its conversion back to the inactive GDP-bound state [37].

Our reaction scheme is based upon the current components established to regulate pheromone signaling. To date there are no reports of scaffolding proteins known to interact with the receptor or the RGS protein in Sz. pombe. Other scaffolding proteins in yeast have been identified within the MAPK cascade (e.g. STE5 in Sc. cerevisiae) although they do not appear to perform any roles in the activation of the G proteins by pheromone-occupied receptors [38]. Further, within yeast, the existence of proteins such as the arrestins (molecules known to modulate GPCR activity in mammalian cells) has not been documented. Recently, in Sc. cerevisiae it has been demonstrated for that SST2 interacts with the C-terminal tail of STE2 (the $\alpha$-factor receptor). It is suggested that this interaction places the SST2 in close proximity to the activated Ga subunit hence enabling rapid hydrolysis of the GTP associated with any activated Ga-GTP terminating the response [39]. In Sz. pombe a similar interaction between Rgs1 and Mam2 (the P-factor receptor) which could antagonize low level-ligand stimulation, while enabling rapid recycling of $\mathrm{G} \alpha$ subunits at high ligand concentrations. While as yet there is no direct evidence of a physical interaction between Mam2 and Rgs1, it is worth noting that, deletion of the C-terminal tail from Mam2 increases 
ligand-independent signaling, and reduces the maximal response consistent with a reduction in Rgs1 activity (Hill et al., in preparation).

Detailed investigation of the model predicted a non-monotone relationship between the concentration of RGS and output from the pathway. This result was validated by subsequent in vivo experiments where the concentration of RGS expressed in cells was manipulated via plasmid-borne expression of the $S z$. pombe RGS protein, Rgs1. In order to explain this relationship and to explore the functional consequences of the existence of a post-signaling state for the Ga, we developed a novel dynamic network motif that captures the underlying structure of the more complex model. This simple structural unit displays all the critical characteristics of the more complex pathway. A similar abstract motif, which captures the underlying structure of most published models of the G protein GTPase cycle, demonstrated that it could not reproduce the non-monotone relationship between maximum output and concentration of RGS. This qualitative behavior is not dependent on the parameter values, alleviating the need for an extensive parameter search on the more detailed kinetic model.

\subsection{Biological implications}

Evidence is emerging to suggest that RGS proteins can play positive roles in GPCR signaling [40]. They have been reported to accelerate the activation kinetics of $\mathrm{G}$ protein-gated potassium channels (GIRK), $\mathrm{Ca}^{2+}$ channels [41-45] and on synaptic transmission [26]. Although the mechanisms within those pathways are not fully understood, some of them may operate mechanistically according to the novel general motif presented in this manuscript.

Modifying the mathematical model so that it simulates a system in which the G $\beta \gamma$ and not the $\mathrm{G} \alpha_{\mathrm{GTP}}$ propagates downstream signaling, results in the RGS acting solely as a negative regulator. Interestingly, this modification makes the system analogous to that of the pheromone-response pathway in Sc. cerevisiae in which the prototypical RGS protein (SST2) was originally described as 
a negative regulator $[27,46-48]$. This suggests the GTPase cycle hypothesis presented here is also

compatible with current understanding of $\mathrm{G} \beta \gamma$-mediated signaling pathways.

The pheromone-response pathway that governs $S z$. pombe mating requires the cells to enter a cell cycle arrest and undergo a change in polarity and extend towards the source of the pheromone (i.e. a mating partner). Therefore, there is an advantage in responding rapidly to a cell that secretes the highest ligand concentration and we suggest that Rgs1 helps to confer this chemotropic advantage. First, Rgs1 narrows the range of effective pheromone concentration by at least one order of magnitude (Fig. 1 and 2). Secondly, Rgs1 serves to reduce the sensitivity of the system thereby raising the threshold concentration at which the cell will respond. Finally, Rgs1 increases the magnitude of the response at levels of stimulation above the threshold. Similar suggestions have been proposed for the $S c$. cerevisiae, where deletion of SST2 appears to cause defects in the cells ability to sense and respond to a pheromone gradient [34].

A non-monotone, unimodal relationship between RGS concentration and maximum signal transmission allows the cell to dynamically adjust and fine-tune the sensitivity and size of response by altering RGS expression levels. Moreover, if RGS expression is driven by the output of the pathway itself, a feedback loop results that allows the system to adapt to average levels of stimulation and become responsive only to sudden upward deflections in the signal. This would allow the yeast cell to respond to the proximity of another cell, regardless of the general background levels of pheromone encountered in its environment.

Our observations have been made in a GPCR signaling cascade and suggest that GTPdependent switches can be more complex than simply $\mathrm{G}_{\operatorname{protein}_{\mathrm{GDP}}}{ }^{\text {(inactive) }}$ and $\mathrm{G}$ protein ${ }_{\mathrm{GTP}}{ }^{\text {(active) }}$. It remains to be determined if this hypothesis can be applied to small monomeric GTP binding proteins as well.

\section{Conclusions}


GPCRs couple to various intracellular signaling pathways via heterotrimeric $G$ proteins that

cycle between GTP and GDP-bound conformations. RGS proteins increase the intrinsic GTPase activity of $\mathrm{G} \alpha$ subunits and are widely regarded as negative regulators of $\mathrm{G}$ protein signaling. Using the pheromone-response pathway in $S z$. pombe as a model G protein-coupled receptor system, we show that abolition of RGS-accelerated GTP hydrolysis reduces the cell's response to maximal stimulation. To explain how RGS proteins act as positive regulators of signaling, a combination of biochemical, genetic and computational approaches has generated a new kinetic model of the $\mathrm{G}$ protein cycle. Our results indicate that RGS proteins enhance signaling through their ability to accelerate GTP hydrolysis on G $\alpha$ subunits that have encountered an effector thereby increasing the supply of Go-GDP that can be activated by GPCRs. Further, by abstracting our computational model of the $\mathrm{G}$ protein cycle we have identified a novel network motif that explains how our model can account for the dual role of GTP hydrolysis. Our demonstration that RGS proteins function as both negative and positive regulators of GPCR signaling has revealed a new perspective on the G protein cycle in which one Ga-GTP activates one effector molecule. 


\section{Figure legends}

Fig. 1

Mutating residues essential for G $\alpha$-mediated GTP hydrolysis reduces maximal pheromone signaling independent RGS activity. Pheromone-dependent transcription of $\beta$-galactosidase expressed from the $s x a 2>l a c Z$ reporter construct was measured in yeast strains; (A) expressing wild type Rgs1 (घ), a chromosomally expressed RGS-insensitive form of Gpa1 (Gpa1 ${ }^{\mathrm{G} 223 \mathrm{~S}}$; $\left.\diamond\right)$ or deleted for Rgs1 ( $\Delta$ Rgs1; $\square)$, (B) deleted for the chromosomal copy of gpal (JY1285) and expressing wild type $(\square)$, an RGS-insensitive $\left(\mathrm{Gpa}^{\mathrm{G} 223 \mathrm{~S}} ; \diamond\right)$ or GTPase deficient $\left(\mathrm{Gpa1} 1^{\mathrm{Q} 244 \mathrm{~L}}, \mathbf{\Delta}\right)$ form of Gpal from a plasmid, (C) deleted for the chromosomal copies of both gpal and rgs 1 (JY1287) and expressing plasmid-derived copies of Gpal ( $\square)$, GTPase deficient Gpa ${ }^{\text {Q244L }}(\boldsymbol{\Delta})$ and both wild type Rgs1 with wild type Gpal (口), (D) containing wild type Rgs1 with a single chromosomal copy $(\square)$ or a chromosomal copy supplemented with a plasmid copy of Gpal (•) of Gpa1, and the Rgs1 deleted strain containing a chromosomal copy ( $\square$ ) or chromosomal copy supplemented with a plasmid copy of Gpa1 (०). Results are means \pm S.E.M. of triplicate determinations from three independent isolates.

\section{Fig. 2}

Deletion of RGS protein has both positive and negative effects on pheromone signaling. Pheromone-dependent transcription of $\beta$-galactosidase $\left(\mathrm{OD}_{420} / 10^{6}\right.$ cells) expressed from the sxa $>$ lac $Z$ reporter construct was measured at 2 hours intervals from 0-16 hours in strains containing ( $\square$ ) wild type Rgs1 or deleted ( $\square$ ) in Rgs1 (Panels A-I). Results are the means \pm standard error of the mean (S.E.M) of triplicate determinations from three separate isolates.

\section{Fig. 3}


A new reaction scheme describing the regulation of a $\mathrm{G}$ protein within a GPCR signaling cascade.

The reaction scheme includes terms for an RGS activity accelerating GTP hydrolysis at two separate stages within the sequence ( $\mathrm{G} \alpha_{\mathrm{GTP}}$ and $\left.\hat{\mathrm{G}} \alpha_{\mathrm{GTP}}\right)$. The binding of a ligand $(\mathrm{L})$ to a receptor $(\mathrm{R})$ is followed by association with a heterotrimeric $\mathrm{G}$ protein $(\operatorname{LRG} \alpha(\beta \gamma))$. Dissociation of the complex generates GTP bound $\mathrm{G} \alpha$-subunit $\left(\mathrm{G} \alpha_{\mathrm{GTP}}\right)$, free $\beta \gamma$-subunits $(\mathrm{G} \beta \gamma)$ and ligand bound receptor (LR).

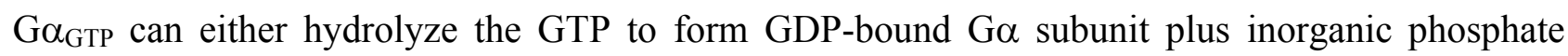
$\left(\mathrm{G \alpha}_{\mathrm{GDP}}+\mathrm{P}\right)$ which can be accelerated by interaction with an RGS (via formation of a $\mathrm{RGSG \alpha} \alpha_{\mathrm{GTP}}$ ) or encounter an effector to form the active $\mathrm{G}^{*}{ }_{\mathrm{GTP}} \mathrm{Effector}$ complex [3]. Following effector activation, $\mathrm{G} \alpha^{*}{ }_{\mathrm{GTP}}$ enters an inert state $\left(\hat{\mathrm{G}} \alpha_{\mathrm{GTP}}\right)$, unable to activate further effectors prior to conversion to $\mathrm{G} \alpha_{\mathrm{GDP}}+\mathrm{P}$ in a reaction that can be accelerated by RGS activity (RGSĜ $\left.\alpha_{\mathrm{GTP}}\right) . \mathrm{G} \alpha_{\mathrm{GDP}}+\mathrm{P}$ reverts to $\mathrm{G} \alpha_{\mathrm{GDP}}(\mathrm{P}$ tends to $\phi)$ and can then re-associate with $\mathrm{G} \beta \gamma$ prior to reactivation by a ligand-bound receptor. The colored boxes enclose the key conceptual sections of the model. The red box indicates the states in which the G protein is inactive, the green box holds the activated (pre-signaling) state and the cyan box holds the inert (post-signaling) state. The orange box contains the pathway regulator; in the purple box, the regulator bound to the pre-signaling state and in the dark blue box, the regulator bound to the post-signaling state.

\section{Fig. 4}

Computational modeling simulates both positive and negative effects of RGS activity on effector output. Reaction parameters for the individual steps $\left(\mathrm{k}_{1} \cdot \mathrm{k}_{17}\right)$ and initial reactant concentrations are supplied in the Supplementary table S1, and S2. The concentration of ligand was varied over the range $0-100 \mu \mathrm{M}$, in simulations of $0-16$ hour's induction (panels A-I) in the presence ( - ) or absence (-) of functional RGS activity. RGS activity was removed from the reaction scheme by reducing its concentration within the model to 0 . Output from the model shows the accumulation of $\mathrm{G}^{*}{ }_{\mathrm{GTP}} \mathrm{Effector}$ complexes over the duration of the simulated assay. 


\section{Fig. 5}

Computational modeling simulates the properties of both $G \alpha$ and $G \beta \gamma$ in regulating effector activation. The concentration of ligand was varied over the range 0-100 $\mu \mathrm{M}$ following simulation of 16 hours induction. Output from the model shows the accumulation of $\mathrm{G \alpha}^{*}{ }_{\mathrm{GTP}}$ Effector complexes over the duration of the simulated assay. (A) Simulations were in the presence ( - ) or absence ( - ) of functional RGS activity or an RGS insensitive $\mathrm{G} \alpha$ subunit $\left(\mathrm{G}^{\mathrm{RGSi}},-\right)$ equivalent to $\mathrm{G} \alpha^{\mathrm{G} 223 \mathrm{~S}}$. The model output is equivalent in the absence of RGS or when RGS is unable to interact with Ga. (B) Simulations in the presence of a GTPase defective and therefore constitutively active form of $\mathrm{G} \alpha\left(\mathrm{G \alpha}^{-\mathrm{GTPase}},-\right)$ equivalent to $\mathrm{G} \alpha^{\mathrm{Q} 244 \mathrm{~L}}$ plus an active RGS species. Data for wild type $\mathrm{G} \alpha(-)$ and $\left(\mathrm{Ga}^{\mathrm{RGSi}},-\right)$ are included for comparison. (C) Simulations in the presence of a GTPase defective and therefore constitutively active form of $\mathrm{G} \alpha\left(\mathrm{G \alpha}^{-\mathrm{GTPase}},-\right)$ in the absence of an RGS

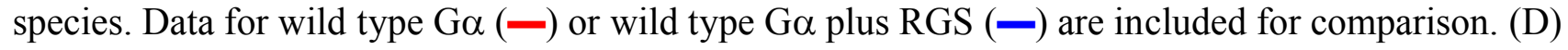
Simulations in the presence of an RGS activity with $1 \mathrm{x}(-)$ or $2 \mathrm{x}(--) \mathrm{G} \alpha$, or in the absence of an RGS activity with $1 \mathrm{x}(-)$ or $2 \mathrm{x}(--) \mathrm{G} \alpha$. (E) Effector output from simulations in which the signal propagator function was converted from $\mathrm{G} \alpha_{\mathrm{GTP}}$ to $\mathrm{G} \beta \gamma$ in the presence (-) and absence (-) of functional RGS activity. The effect of rendering the Ga subunit GTPase deficient $\left(\mathrm{G}^{-\mathrm{GTPase}},-\right)$ in the presence of an RGS activity was also simulated.

\section{Fig. 6}

Using a combination of experimental and computational approaches to investigate the relationship between output and concentration of RGS. The concentration of RGS in the model or in the yeast was varied over the range 0-3 fold for varying concentrations $(0-100 \mu \mathrm{M})$ of ligand (model) or pheromone (in vivo) following 16 hours induction. (A) Simulations in the presence of $1 \mathrm{x}(-), 2 \mathrm{x}$ $(-)$ and $3 \times$ ( - ) RGS or No RGS (-). Output from the model shows the accumulation of

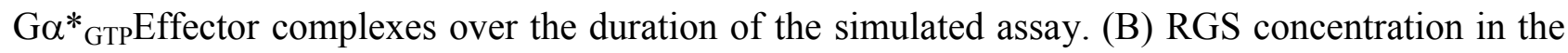
yeast was manipulated either by deleting the chromosomal copy ( - ) and then introducing 1 
plasmid copy of Rgs1 $(1 \mathrm{x},-), 2$ plasmid copies of $\operatorname{Rgs} 1(2 \mathrm{x},-)$ or 2 plasmid copies with the

chromosomal copy of $\operatorname{Rgs} 1(3 \mathrm{x},-)$. Output from the in vivo experiments used the pheromonedependent transcription of $\beta$-galactosidase expressed from the $s x a 2>l a c Z$ reporter construct and are means \pm S.E.M. of triplicate determinations from three independent isolates. (C) Simulating the accumulation of $\mathrm{G \alpha}^{*}{ }_{\mathrm{GTP}}$ Effector complexes over a range of RGS (0-300 nM) and ligand concentrations $(0-100 \mu \mathrm{M})$. (D) Plotting the mean ( \pm S.E.M) $\beta$-galactosidase expression levels against the number of copies of the $\operatorname{rgs} 1$ gene expressed within the yeast. (C) and (D) demonstrate that the relationship between response and concentration of RGS, both in the model and in vivo, is non-monotone.

\section{Fig. 7}

A dynamic motif for $\mathrm{G}$ protein signaling. Abstraction of the reaction scheme shown in Fig. 3 (in terms of the sections represented by the colored boxes), generates a simple network motif (A). X can attain three states, $\mathrm{X}^{\circ}$, the basal unstimulated state (compare with $\left.\mathrm{G} \alpha_{\mathrm{GDP}}\right), \mathrm{X}^{[1]}$, a pre-signaling state (compare with $\mathrm{G} \alpha_{\mathrm{GTP}}$ ), and $\mathrm{X}^{[2]}$, a post-signaling state (compare with $\hat{\mathrm{G}} \alpha_{\mathrm{GTP}}$ ). The free regulatory molecule, $\mathrm{R}^{\circ}$ (compare with the RGS protein), can bind both states of the signaling molecule, leading to $\mathrm{R}^{[1]}$ and $\mathrm{R}^{[2]}$ respectively, and promotes their return to the basal state, $\mathrm{X}^{\circ}$, simultaneously freeing $\mathrm{R}^{\circ}$. Transitions between states are controlled by the rate constants $\left(\sigma, \gamma, \alpha, \beta, \mu_{\alpha}, \mu_{\beta}\right)$. Output occurs when the signaling molecule makes the transition between $\mathrm{X}^{[1]}$ and $\mathrm{X}^{[2]}$. (B) The relationship between maximum output and the quantity of free-regulatory molecule, for the motif in $\mathrm{A}$ is sufficient to produce the dynamical properties that give rise to the non-monotone behavior demonstrated by the in vivo data. (C) Removal of the post-signaling state $\left(\mathrm{X}^{[2]}\right)$ from the motif in $\mathrm{A}$, produces a network motif where the regulatory molecule acts solely as a negative regulator of maximal steady state output (D). This network motif depicts the underlying structure of many existing G protein GTPase models and hypotheses (see Supplementary text). For 
both motifs the steady state output flux of the system is the product $\gamma \mathrm{X}^{[1]}$, (the rate of transition 1 from pre- to post-signaling state) and has been determined when the input is at its maximum.

2

4

5

6

7

8

10

11

12

13

14

15

16

17

18

19

20

21

22

23

24

25

26

27

28

29

30

31

32

33

34

35

36

37

38

39

40

41

42

43

44

45

46

47

48

49

50

51

52

53

54

55

56

57

58

59

60

61

62

63 


\section{Acknowledgements}

This work was supported by an EPSRC pre-doctoral traineeship (B.S.), BBSRC CASE studentships with AstraZeneca (C.H.), the University Hospitals of Coventry and Warwickshire NHS Trust (L.G, S.T, and G.L.) and the BBSRC (G.L.) grant number (BB/G01227X/1). We thank Eilish McCann, Graham Medley, Alex Conner, Elliott Ross and Alan Goddard for discussions. 


\section{References}

1. S.R. Sprang, Annu. Rev. Biochem. 66 (1997) 639-678.

2. C.A. Johnston, D.P. Siderovski, Mol. Pharmacol. 72 (2007) 219-230.

3. E.M. Ross, T.M. Wilkie, Annu. Rev. Biochem. 69 (2000) 795-827.

4. G.B. Willars, Semin. Cell. Dev. Biol. 17 (2006) 363-376.

5. G. Ladds, J. Davey, Trends Biotechnol 23 (2004) 367-373.

6. J. Davey, Yeast 14 (1998) 1529-1566.

7. H.G. Dohlman, Annu. Rev. Physiol. 64 (2002) 129-152.

8. H.G Dohlman, Thorner, J. J. Biol. Chem. 272 (1997) 3871-3874.

9. C.S. Hoffman, Eukaryot. Cell. 4 (2005) 495-503.

10. T. Obara, M. Nakafuku, M. Yamamoto, Kaziro, Y. Proc. Natl. Acad. Sci. USA 88 (1991) $5877-5881$.

11. C. Hill, A. Goddard, J. Davey, G. Ladds, Semin. Cell. Dev. Biol. 17 (2006) 352-362.

12. G. Ladds, A. Goddard, C. Hill, S. Thornton, J. Davey, Cell. Signal. 19 (2007) 103-113.

13. J. Davey, EMBO J. 11 (1991) 951-960.

14. P. Watson, K. Davis, M. Didmon, P. Broad, J. Davey, Mol. Microbiol. 33 (1999) 623-634.

15. P.S. Pereira, N.C. Jones, Genes. Cells. 6 (2001) 789-802.

16. M. Didmon, K. Davis, P. Watson, G. Ladds, P. Broad, Davey, J. Curr Genet 41 (2002) 241253.

17. G. Ladds, K. Davis, A. Das, J. Davey, Mol. Microbiol. 55 (2005) 482-497.

18. J. Davey, R. Egel, O. Nielsen, in Adolph KW (Ed), Methods in Molecular Genetics, Pheromone procedures in fission yeast, San Diego, 1995, pp. 247-263.

19. G. Ladds, E.M. Rasmussen, T. Young, O. Nielsen, J. Davey, Mol. Microbiol. 20 (1996) 35-42.

20. G. Ladds, K. Davis, E.W. Hillhouse, J. Davey, Mol. Microbiol. 47 (2003) 781-792.

21. K. Maundrell, Gene 123 (1993) 127-130.

22. K. Davis, G. Ladds, A. Das, A. Goddard, Davey, J. Mol. Biotechnol. 28 (2004) 201-204. 
23. P. DiBello, T. Runyan-Garrison, D.M. Apanovitch, G. Hoffman, D.J. Shuey, K. Mason, M.I.

Cockett, H.G. Dohlman, J. Biol. Chem. 273 (1998) 5780-5784.

24. S. Landry, M.T. Pettit, E. Apolinario, C.S. Hoffman, Genetics 154 (2000) 1463-1471.

25. J.J. Carrillo, P.A. Stevens, G. J. Milligan, Pharmacol. Exp. Ther. 302 (2002) 1080-1088.

26. H. Zhong, S.M. Wade, P.J. Woolf, J.L. Linderman, J.R.Traynor, R.R. Neubig, J. Biol. Chem. 278 (2003) 7278-7284.

27. N. Hao, N. Yildirim, Y. Wang, T.C. Elston, H.G. Dohlman, J. Biol. Chem. 278 (2003) 4650646515 .

28. B. Kofahl, E. Klipp, Yeast 21 (2004) 831-850.

29. N. Yildirim, N. Hao, H.G. Dohlman, T.C. Elston, Methods Enzymol. 389 (2004) 383-398.

30. S.J. Bornheimer, M.R. Maurya, M.G. Farquhar, S. Subramaniam, Proc. Natl. Acad. Sci. USA 101 (2004) 15899-15904.

31. A.B. Goryachev, A.V. Pokhilko, PLoS Comput. Biol. 2 (2006) 1511-1521.

32. M. Turcotte, W. Tang, E.M. Ross, PLoS Comput. Biol. 4 (2008) e1000148.

33. J.J. Linderman, J. Biol. Chem. (2008) DOI: 10.1074/jbc.R800028200.

34. T.I. Moore, C.C. Chou, Q. Nie, N.L. Jeon, T. Yi, PLoS ONE 3 (2008)e3865.

35. U. Alon, Nature 446 (2007) 497.

36. A.G. Gilman, Annu. Rev. Biochem. 56 (1987) 615-649.

37. B. Cook, M. Bar-Yaacov, H.C. Ben-Ami, R.E. Goldstein, Z. Paroush, Z. Selinger, B. Minke, Nat. Cell. Biol. 2 (2000) 296-301.

38. N. Hao, S. Nayak, M. Behar, R.H. Shanks, M.J. Nagiec, B. Errede, J. Hasty, T.C. Elston, H.G. Dohlman, Mol. Cell. 30 (2008) 649-656.

39. D.R. Ballon, P.L. Flanary, D.P. Gladue, J.B. Konopka, H.G. Dohlman, J. Thorner, Cell 126 (2006) 1079-1093.

40. G. Milligan, Trends Endocrinol. Metab. 9 (2008) 13-19. 
41. C.A. Doupnik, N. Davidson, H.A. Lester, and P. Kofuji, Proc. Natl. Acad. Sci. USA 94 (1997) 10461-10466.

42. O. Saitoh, Y. Kubo, M. Odagiri, M. Ichikawa, K. Yamagata, T. Sekine, J. Biol. Chem. 274 (1997) 9899-9904.

43. N. Zerangue, L.Y. Jan, Curr. Biol. 8 (1998) R313-R316.

44. S.W. Jeong, S.R. Ikeda, J. Neurosci. 20 (2000) 4489-4496.

45. A. Tinker, Semin. Cell. Dev. Biol. 17 (2006) 377-382.

46. R.K. Chan, C.A. Otte, Mol. Cell. Biol. 2 (1982a) 21-29.

47. R.K. Chan, C.A. Otte, Mol. Cell. Biol. 2 (1982b) 11-20.

48. H.G. Dohlman, D. Apaniesk, Y. Chen, J. Song, D. Nusskern, Mol. Cell. Biol. 15 (1995) 36353643. 
Figure 1
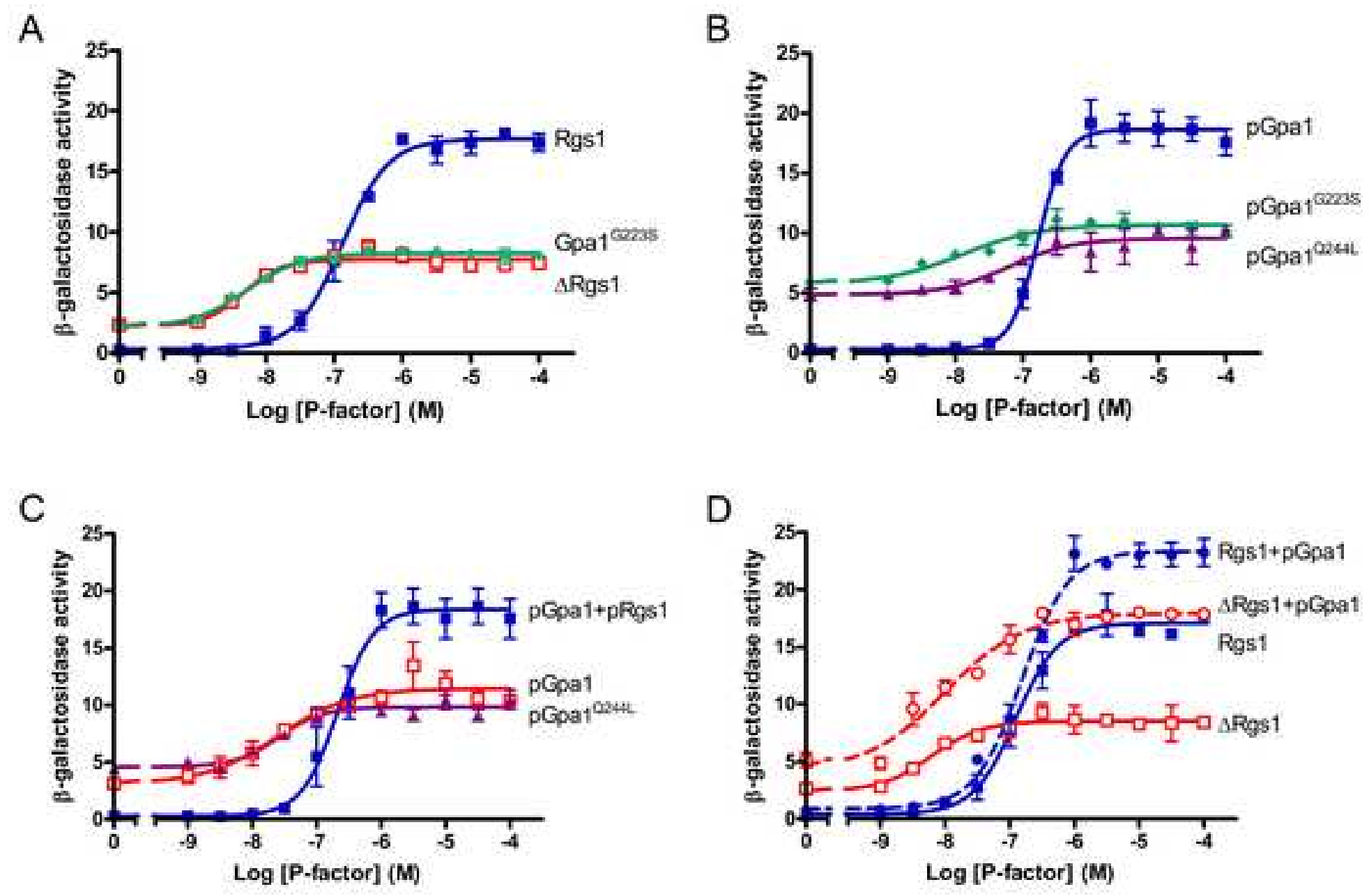
Figure 2
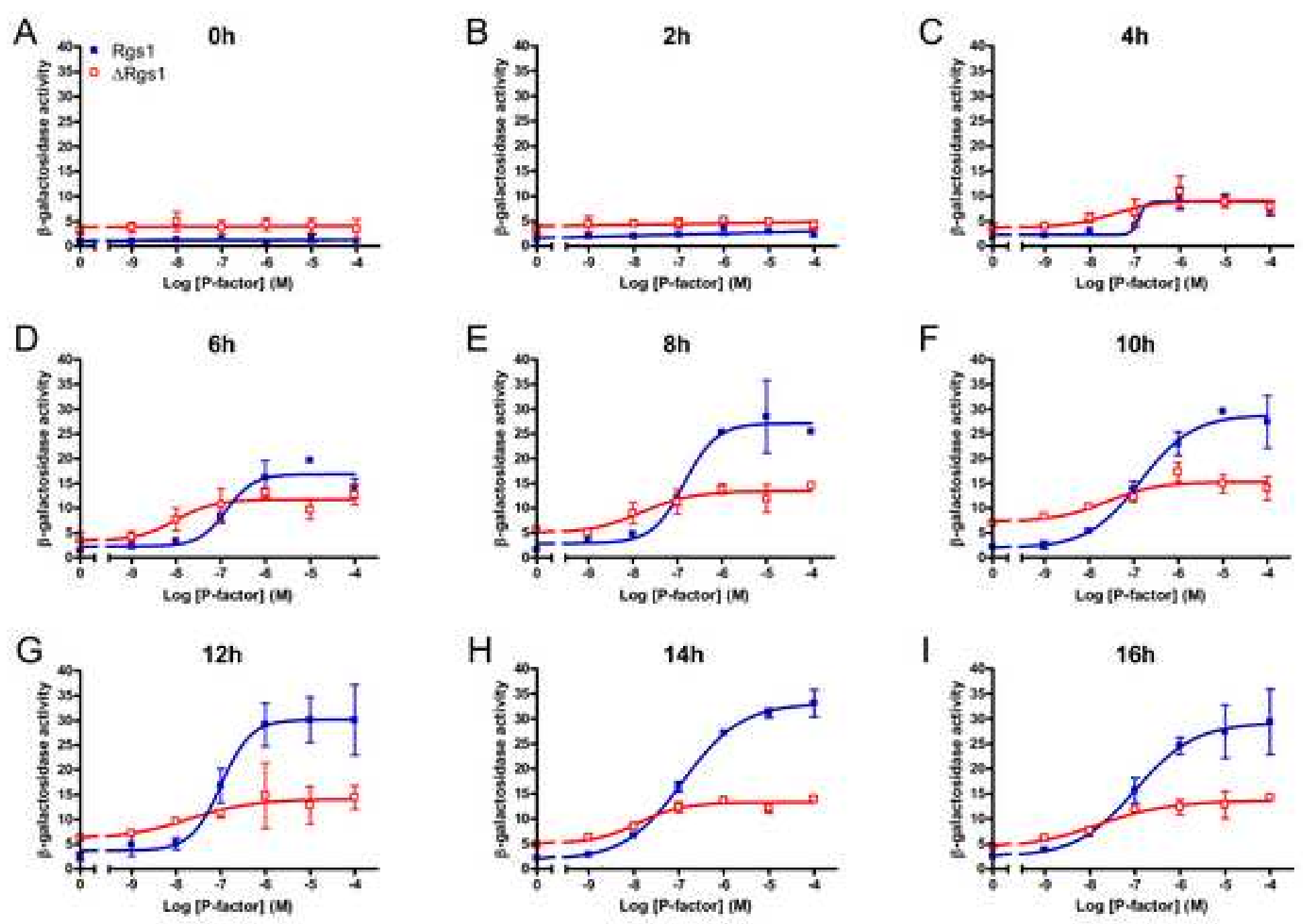
Figure 3

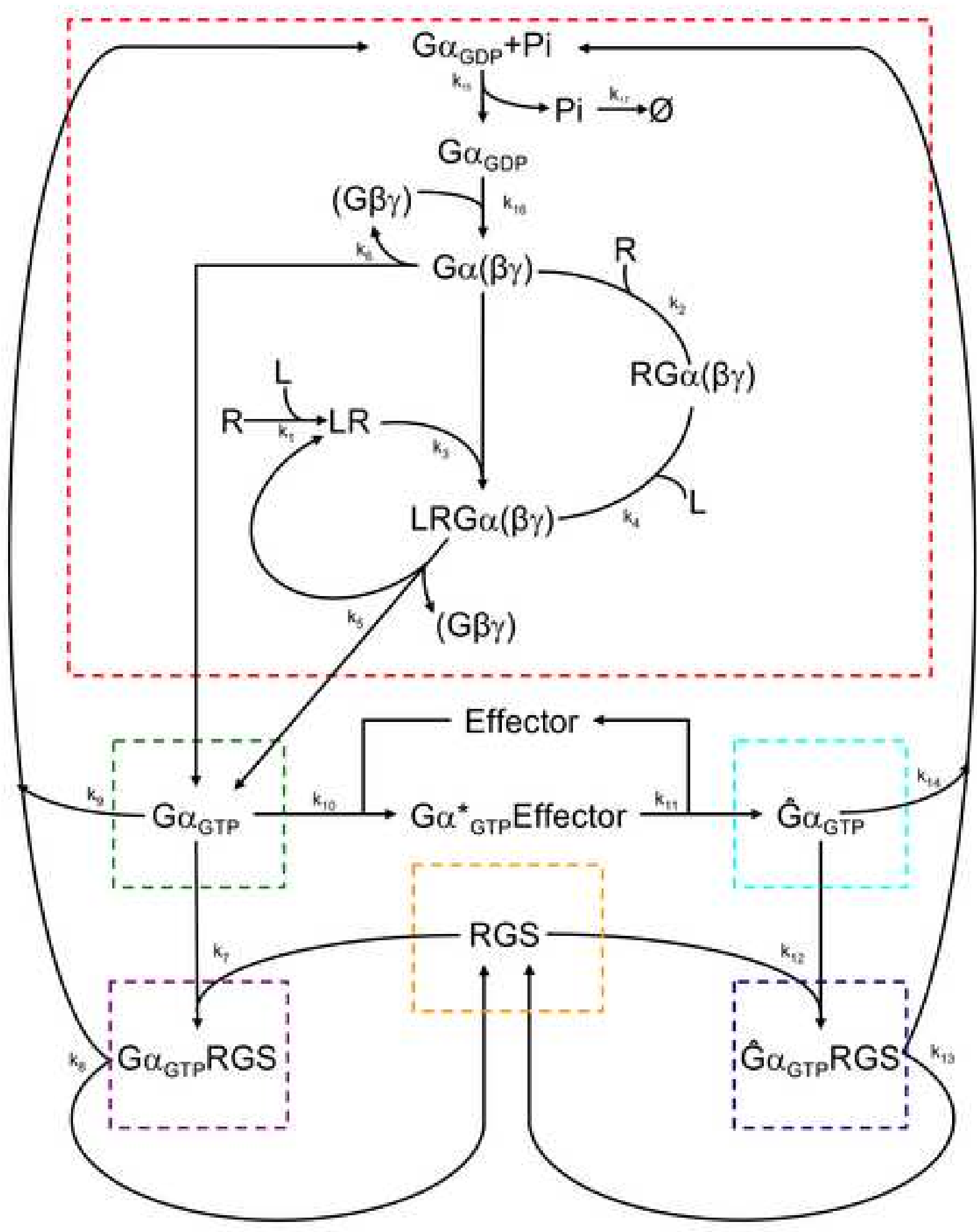


Figure 4
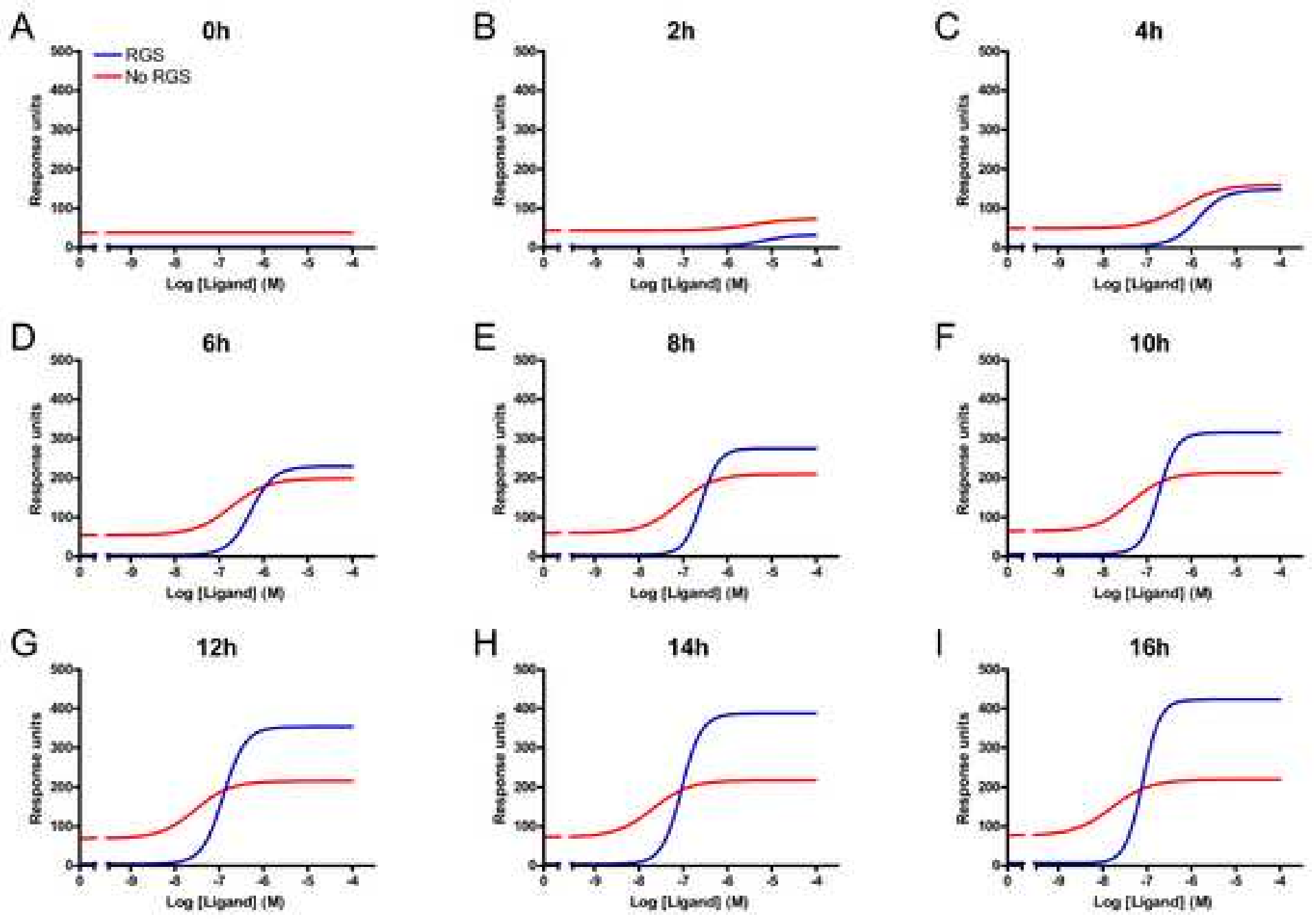
Figure 5
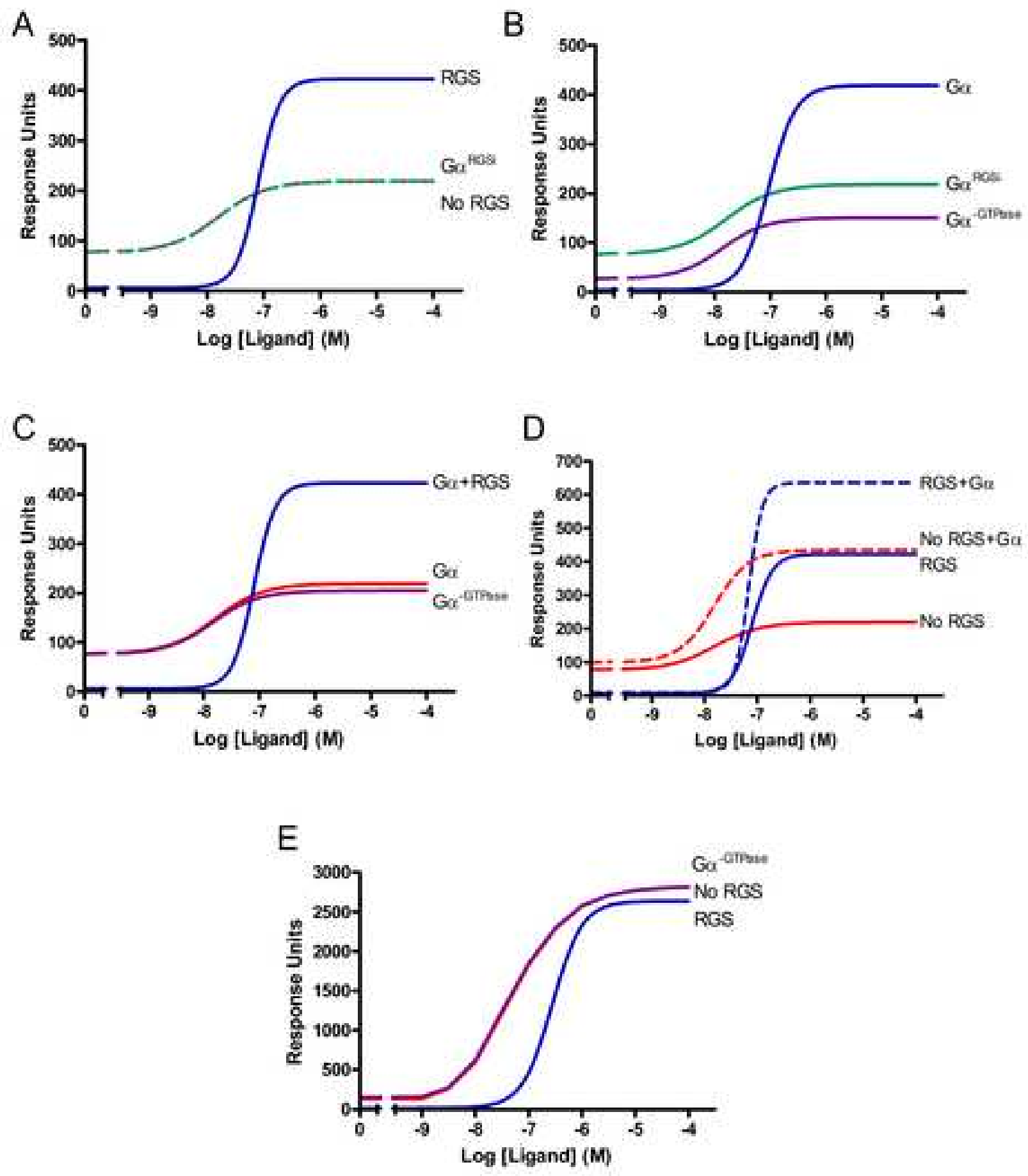


\section{Figure 6}

A

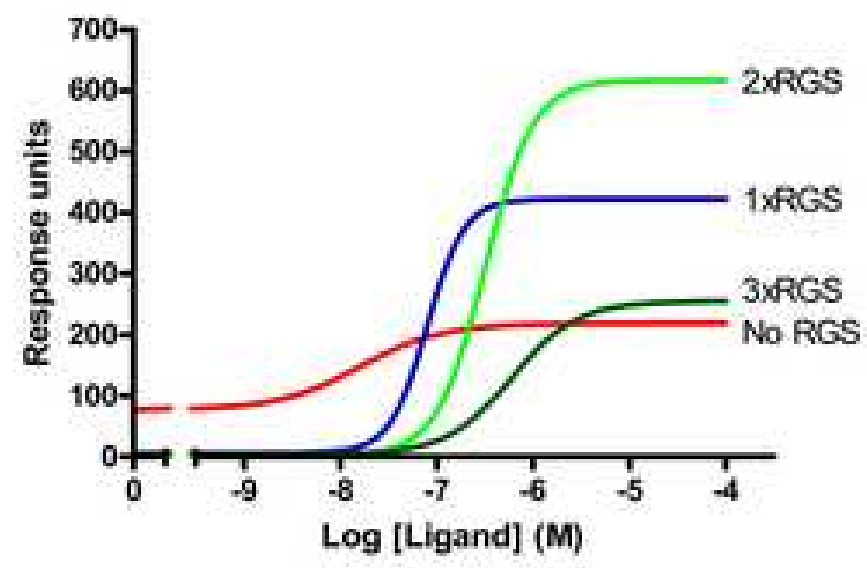

C

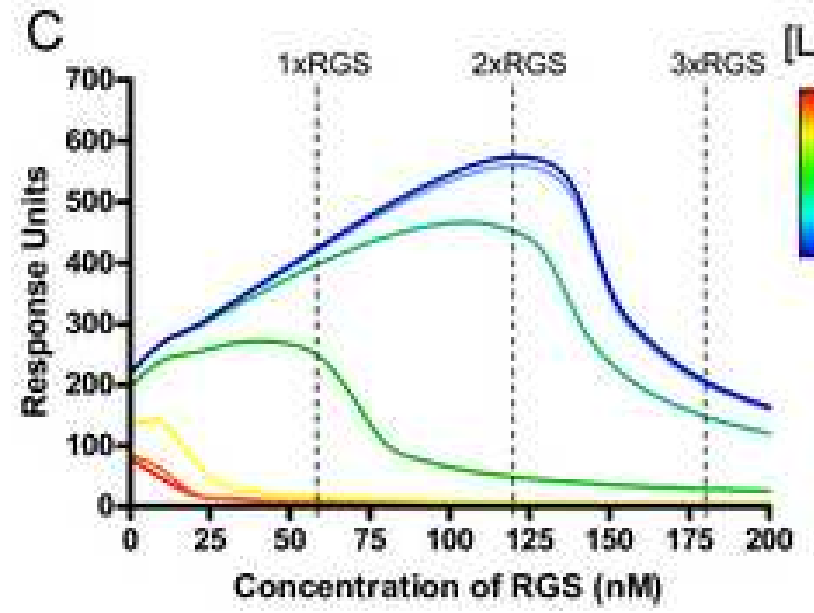

B

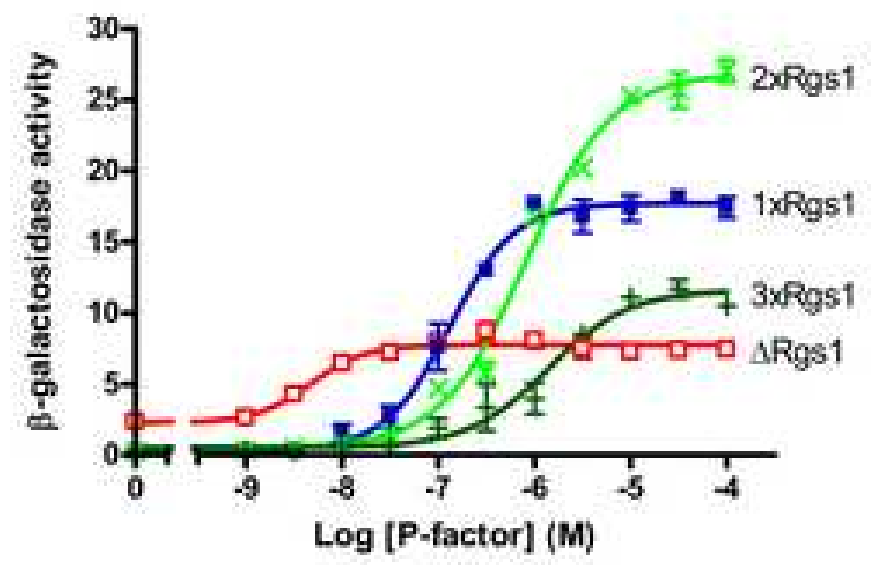

D [Ligand]

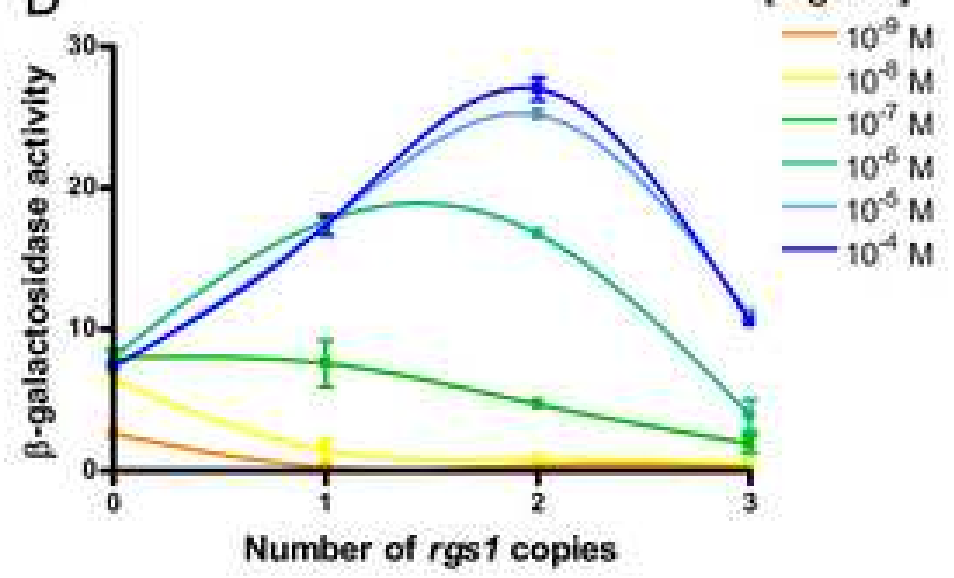


Figure 7

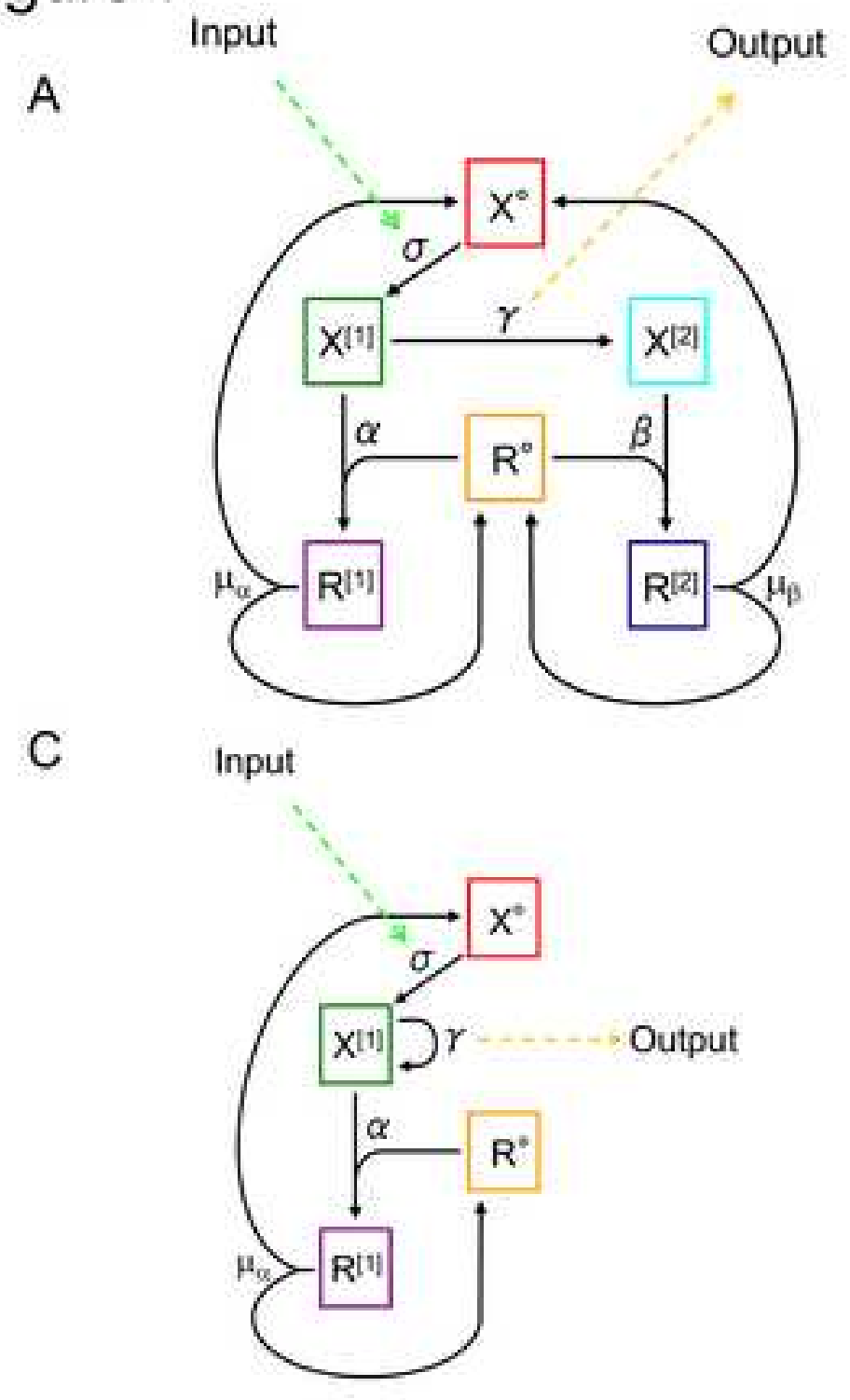

B

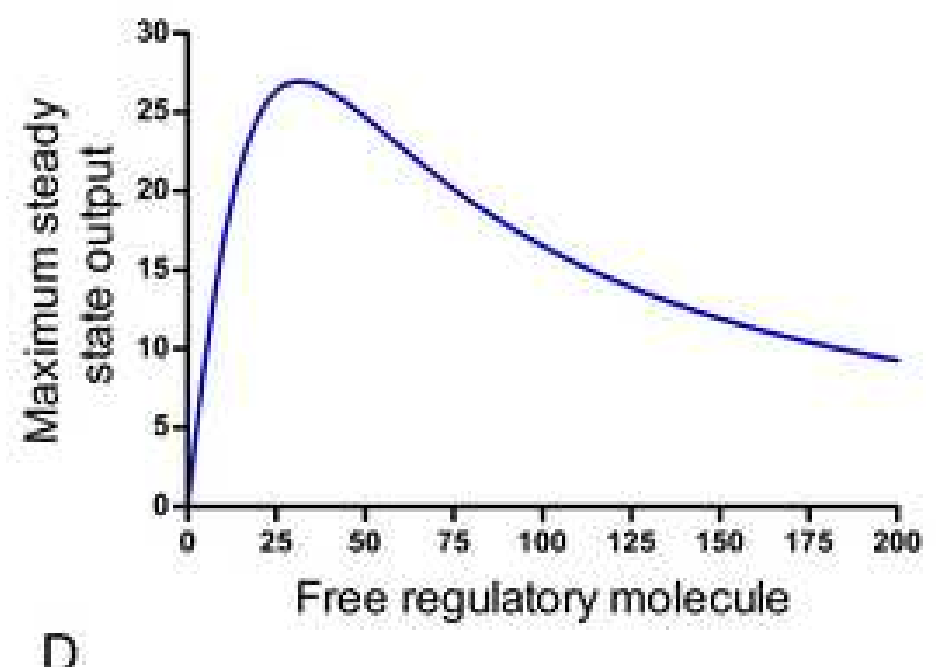

D

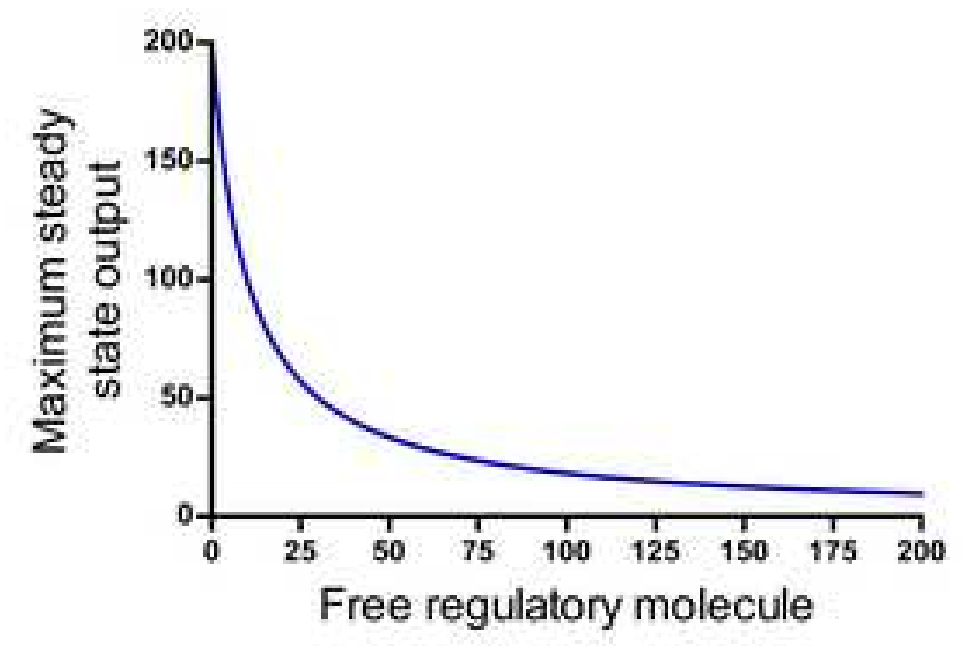




\section{Click here to download Supplementary Material: Supplementary complete.pdf}

Supplementary Material
Click here to download S 